\title{
EL GÉNERO ÉPICO EN ESPAÑA: DE LOS POEMAS MAYORES AL CANTO ÉPICO
}

José Cebrián

A principios del siglo XVII la poesía épica culta -y con ella el subgénero mitológico- llevaba ya en España más de media centuria de prolongada fecundidad. Es una realidad tangible el hecho cierto que desde la segunda mitad del siglo XVI hasta bien entrado el primer tercio del siglo XVII llegó a convertirse en uno de los géneros de mayor cultivo y aceptación. Y ello se debió, sobre todo, al éxito que alcanzó esta clase de poesía, destinada a la lectura prolongada, entre el público. La cantidad ingente de piezas épicas publicadas a lo largo de ambas centurias es prueba irrefutable. «No cabe duda que la poesía narrativa, a diferencia de la lírica - son palabras de F. Pierce-se hizo muy asequible, y desde luego se leyó extensamente. Tampoco sería exagerado afirmar que esto refleja el prestigio conocido del género entre la gente culta de una época en un momento en que un soneto o una oda ocupaba un lugar modesto en la escala de valores estéticos y el epos representaba, en cambio, la empresa más seria para un poeta, neófito o consagrado» ${ }^{1}$.

La mayor parte de los críticos que han enjuiciado nuestra poesía narrativa se han aprestado a considerarla, poco más o menos, como un «género fallido», carente de auténticas obras maestras, y deudor en exceso de la épica italiana renacentista. Se la ha tildado de farragosa, de abundante en tópicos y de prosaísmo acusado $^{2}$, de servilismo en la imitación de sus modelos, de torpe en la elección

1 Frank Pierce: La poesía épica del Siglo de Oro. Madrid, Ed. Gredos, $1968^{2}$, p. 27.

2 «El prosaísmo es otro morbo de la Épica erudita. Muchos de esos versos no pueden tener la soltura y la elegancia apetecidas, porque la mayor parte de los poetas usaban el procedimiento de concebir las ideas en prosa y luego versificarlas. Encontrábanse, además, en la insuperable dificultad de tener que supeditarse a las exigencias de los modelos, lo cual forzaba su pluma, limitaba su iniciativa y cortaba las alas a la inventiva particular». Antonio Papell: "La poesía épica culta de los siglos XVI y XVII», en Historia general de las literaturas hispánicas. Barcelona, Ed. Barna, 1951, vol. II, pp. 755-776. 
del metro y de falta de habilidad constructiva. Juicios disculpables si lo que se persigue en este género es cierta originalidad anacrónica y se menosprecia tanto la estructura interna de estas obras como el aparato retórico que las caracteriza.

La épica culta parte del concepto de la imitatio homérica y de la preceptiva aristotélica atendiendo con prioridad a la idea del «imposible-verosímil» (Poéti$c a, \mathrm{XXIV}, 12)$. El poema, guiado por el modelo clásico, aparece dividido en un número variable de cantos y comienza con un prohemio ritual en el que se declara, casi siempre, el argumento, se invoca a las Musas o a Febo (a Dios y a sus santos en las obras de asunto religioso), y se capta la benevolencia del mecenas con fórmulas propias del retoricismo grecolatino según una tópica repetitiva ${ }^{3}$. La obra reviste, además, - la mayoría de las veces - la forma de la octava real u ottava rima, aceptada en España en los albores del siglo XVII tanto como la silva o como el soneto. «Gran parte de la poesía solemne del Siglo de Oro fue escrita en octavas reales; este esquema métrico, a la vez que permitía todos los sutiles matices del endecasílabo, daba a la poesía una gravedad y una elegancia que no poseía el muy tradicional pie del romance, con todas sus virtudes, ni el verso de arte mayor, de vida más corta. La nueva épica [...] conservó casi siempre su uniformidad en el aspecto formal. La octava llegó a ser tan inseparable de la «buena poesía» (en frase de Velázquez) como el endecasílabo mismo [...] También llegó a emplearse con propósitos de menores vuelos y alcance para la poesía panegírica [...] Igualmente se empleó en fábulas entre líricas y narrativas, como la exquisita Fábula del Genil de Espinosa. El canto épico, forma breve y ligada por su longitud a estas últimas, aunque de claro tipo heroico, estaba escrito generalmente en octavas [...] A poco que se busquen en las bibliografías datos de la épica del Siglo de Oro, se comprobará cuánto se empleaban las octavas y para cuántos temas distintos, sin perder nunca su tono elevado, vehículo fácil, por lo general, para la adulación y la lisonja de posibles mecenas» ${ }^{4}$.

No todos los poemas narrativos se escribieron en octavas. Frente al verso endecasílabo y a sus combinaciones, los esquemas de la versificación tradicional fueron los preferidos por algunos poetas y se adaptaron también a asuntos diversos. El infelice robo de Elena (1582) de Joaquín Romero de Cepeda, en diez cantos, está compuesto en quintillas, lo mismo que el Isidro (1599) de Lope de Vega. El Fernando, o Sevilla restaurada (1632) de Juan Antonio de Vera y Figueroa lo está en redondillas. También se emplearon otras estrofas italianas. El terceto (la terza rima) configura poemas de índole tan diferente - pondremos sólo dos ejemploscomo la Década de la Passión de Jesu Christo (1576) de Juan de Coloma, o el Exemplar poético (1606) de Juan de la Cueva. La Gatomaquia (1634) de Lope de Vega y los Fragmentos de Adonis (1619?) de D. Pedro Soto de Rojas están

3 Vid. Ernst Robert Curtius: Literatura europea y Edad Media latina. México, Fondo de Cultura Económica, 1981 [3. reimpr.], I, pp. 126-138. Vid. también Antonio Prieto: «Del ritual introductorio en la épica culta», en Estudios de literatura europea. Madrid, Ed. Narcea, 1975, pp. 15-75; Antonio Prieto: "Origen y transformación de la épica culta en castellano», en Coherencia y relevancia textual. De Berceo y Baroja. Madrid, Ed. Alhambra, 1980, esp. pp. 117-120; y más recientemente, «La poesía épica renacentista», en La poesía española del siglo XVI. Madrid, Eds. Cátedra, 1984-1987, 2 vols., pp. 781-831.

4 F. Pierce: La poesía épica..., pp. 222-223. 
escritos en silvas. Tampoco puede olvidarse la ingente cantidad de poemas narrativos que fueron compuestos en endecasílabo libre, el «suelto italiano», sin duda el metro romance que más se asemejaba al hexámetro. Y ello, tanto en traducciones como en poemas de corte épico. De los segundos pueden citarse innumerables exponentes de temática harto variada: la Fábula de Hero y Leandro (1543) de Juan Boscán, la Felicíssima victoria (1578) de Jerónimo Corte Real, los Amores y muerte de Adonis (1578) de Jerónimo de Lomas Cantoral, el Luzero de la Tierra Sancta (1587) de Pedro de Escobar Cabeza de Vaca, la Contienda de Áyax Telamonio y Ulises sobre las armas de Achiles (1591) de Hernando de Acuña, La Muracinda (1604?) —con los parlamentos en octavas- de Juan de la Cueva, la Historia de la Nueva México (1610) de Gaspar Villagrá, o los Amantes de Teruel (1616) de Juan Yagüe de Salas. Traducciones que destacaron por su éxito y aceptación fueron la Ulyxea (primera edición completa, 1556) de Gonzalo Pérez - muchas veces reimpresa-, y la versión de la Eneida (1555), en octavas y verso suelto, de Gregorio Hernández de Velasco.

Las traducciones de las grandes obras de Homero, Virgilio, Ovidio y Lucano contribuyeron a la consolidación y al afianzamiento de la épica culta en España. Las reediciones continuas de la Ulyxea de Gonzalo Pérez —-1550, 1553, 1556, 1562, etc. - realizada directamente del original griego, demuestran su aceptación y éxito $^{5}$. Una acogida similar debió gozar la traducción completa de la Eneida de Gregorio Hernández de Velasco, reimpresa también en varias ocasiones entre 1555 y 1614. La traducción en prosa de La Farsalia de Lucano, debida a Martín Lasso de Oropesa, vio la luz varias veces también entre 1541 y 1578. Mas fue Ovidio el poeta latino que más se vertió en lengua castellana. La difusión y fama de las Metamorfosis, auténtico libro de cabecera de los cultivadores de la temática mitológica, épicos o no, está atestiguada por las diversas versiones que aparecieron a lo largo del siglo XVI: desde la primitiva de Jorge de Bustamante, en prosa, muy divulgada, hasta las mejor logradas de Antonio Pérez Sigler (1580) y de Pedro Sánchez de Viana (1589), ambas en verso, la primera en «suelto y octava rima» y la segunda en «tercetos y octavas reales», y otras menos conocidas como la incompleta de Felipe Mey (1586) ${ }^{6}$.

La épica italiana había ofrecido a Europa como poema modélico renacentista el Orlando furioso (primera edición, 1516; tercera edición definitiva -46 cantos-1532) de Ludovico Ariosto (1474-1532), continuación relativa de la temática emprendida por Matteo Maria Boiardo (1434-1494) en el Orlando innamorato (1495, 69 cantos), cuya aportación más relevante consistió en la conjunción de los ciclos bretón y carolingio. La obra de Ariosto se asentó en tres pilares temáticos esenciales: el amor de Orlando por Angélica, las escaramuzas y los combates entre cristianos e islamitas en las cercanías de París, y el amor novelesco

5 Vid. Marcelino Menéndez Pelayo: Biblioteca de traductores españoles. Madrid, CSIC, 1952-1953, 4 vols., IV, pp. 35-36.

6 Vid. G. Highet: The Classical Tradition. Greek and Roman Influences on Western Literature. New York-London, Oxford University Press, 1949, pp. 114-117 [hay trad. esp.: México-Buenos Aires, 1954, 2 vols.]; María Rosa Lida de Malkiel: La tradición clásica en España. Barcelona, Ed. Ariel, 1975, esp. pp. 369-372. Sobre la importancia de los poemas de Virgilio y de Lucano, vid. F. Pierce: La poesía épica..., pp. 21-22. 
de Bradamante y Ruggero. Su influjo en la épica hispánica, así como en otros géneros, se dejó sentir con especial intensidad en la segunda mitad del siglo XVI merced, sobre todo, a la famosa traducción realizada por Jerónimo Ximénez de Urrea $(1549)^{7}$, de grande éxito y continuas reediciones a lo largo de los cincuenta años siguientes ${ }^{8}$, y a las menos afortunadas de Hernando de Alcocer (1550) y de Diego Vázquez de Contreras (1585) ${ }^{9}$. En cierta medida contribuyó a su difusión y estima la alta consideración de que gozaba en el siglo XVI y que la presentaba como una nueva Eneida, atiborrada de elementos fantásticos y caballerescos y de sentencias morales. No puede olvidarse tampoco la réplica española del poema italiano, La segunda parte del Orlando (1555) de Nicolás Espinosa, inserta también en la corriente de exaltación nacional con Bernando del Carpio como héroe hispano arquetípico ${ }^{10}$. Obras de la categoría de La Araucana (primera parte, 1569) de Alonso de Ercilla, Las lágrimas de Angélica (1586) de Luis Barahona de Soto, La hermosura de Angélica (1602) de Lope de Vega, o El Bernardo (1624) de Bernardo de Balbuena acusan, en mayor o en menor grado, el influjo ariostesco ${ }^{11}$.

En los últimos años del siglo XVI se produjo un cambio gradual en las preferencias de los poetas. El Furioso, considerado hasta entonces como paradigma fiel que aunaba los elementos propios del romanzo y el didactismo moralizante, cedió su lugar preeminente a los nuevos cauces abiertos por la Gerusalemme liberata (1581) de Torquato Tasso (1544-1595). Ello estuvo propiciado, sobre todo, por el espíritu emanado de Trento, por la restauración de la preceptiva clasicista neoaristotélica y por el interés suscitado por la historia y por los asuntos religiosos a principios del siglo siguiente. «Lo que había de sugestionar necesariamente a los escritores españoles de la Contrarreforma - ha escrito J. Arce- era un tipo de poema épico que permitía hacer compatibles las exigencias de la forma virgiliana con un contenido moderno, es decir, cristiano. A ninguna historia, quizá, como a la nuestra le era fácilmente adaptable un arquetipo basado en la lucha de cristianos contra infieles, en la que el triunfo de los primeros, gracias a la intervención divina, se logra contra los poderes infernales que se oponen a ellos. Tasso es, según una interpretación casi tópica, un nuevo Virgilio, un Virgilio cristiano en quien está la fórmula que permite cristianizar la antigua materia épica. Por ello, ya desde los dos últimos decenios del siglo XVI, pero sobre todo a lo

7 Jerónymo de Urrea: Orlando furioso, traducido en Romance Castellano. Anuers, Martin Nucio, 1549.

8 Vid. F. Pierce: La poesía épica..., p. 367.

9 Ibidem.

10 Vid. Esther Lacadena: «La segunda parte del Orlando», en Nacionalismo y alegoría en la épica española del XVI: «La Angélica» de Barahona de Soto. Zaragoza, Universidad de Zaragoza, 1980, pp. 195-203.

11 Sobre la influencia del poema ariostesco en la épica hispánica resulta imprescindible la obra de Maxime Chevalier: L'Arioste en Espagne (1530-1650). Recherches sur l'influence du «Roland furieux». Bordeaux, Institut d'Études Ibériques, 1966, pp. 218-236. Sobre la influencia de la Angélica de Barahona, vid. E. Lacadena: Nacionalismo y alegoría..., pp. 127-164. Un estudio de relieve es el que trae la ed. de José Lara Garrido: Luis Barahona de Soto. Las lágrimas de Angélica. Madrid, Eds. Cátedra, 1981, esp. pp. 23-71. 
largo del XVII, la sustitución como modelo épico de Ariosto por Tasso va siendo paulatina hasta acabar con la primera; o, lo que es lo mismo: al tipo de poema novelesco o fantástico, se va superponiendo el poema épico cristiano e histórico que responde plenamente a las aspiraciones del lector español de la época» ${ }^{12}$.

Las traducciones castellanas se realizaron pocos años después de la edición italiana completa (1581) en veinte cantos. La primera apareció en 1587 bajo el título de Ierusalem libertada de la mano de Juan Sedeño ${ }^{13}$. Por aquellas mismas fechas el canónigo Bartolomé Cairasco (1540-1610) concluyó la suya, nominándola Goffredo famoso. No tuvo la fortuna suficiente y permanecio inédita hasta fechas recientes (1967) ${ }^{14}$. De 1649 data la edición de una tercera versión, obra de Antonio Sarmiento de Mendoza, titulada Gierusalemme liberata ${ }^{15}$. Todas fueron vertidas en octavas ${ }^{16}$.

El influjo de la Gerusalemme liberata se dejo sentir, desde muy pronto, en un número considerable de poemas narrativos españoles. «En España los poemas de «liberación» parecían ir tan bien a las inclinaciones de los poetas y a los deseos de sus lectores que surgieron no pocos de ellos en la primera mitad del siglo XVII. Cierto que el terreno estaba bien abonado, pues [...] los españoles contaban ya con muchas epopeyas sobre su historia medieval y moderna; es decir, los poemas de tema histórico encajaban perfectamente en sus gustos más arraigados. Además, como abundaban los poemas religiosos, la combinación de heroísmo y fe, tal como se daba en la historia de las Cruzadas, no podía menos de tener fácil aceptación en el Siglo de Oro» ${ }^{17}$. El papel pionero corresponde con todos los honores a Cristóbal de Mesa (1561-1633) autor de hasta tres composiciones. La primera, las Navas de Tolosa (1594), ofrece una estimable copia de elementos tassescos: desde los materiales retóricos del prohemio — calcados del modelo- hasta la división en veinte cantos. Lo mismo se observa en La restauración de Espa$\tilde{n} a$ (1607), en diez cantos, y acaso algo menor en El patrón de España, en seis

12 Joaquín Arce: Tasso y la poesía española. Repercusión literaria y confrontación lingüística. Barcelona, Ed. Planeta, 1973, pp. 34-35. Vid. también Arturo Farinelli: «Tasso in Ispagna. Una versione inedita della Gerusalemme», en Italia e Spagna. Torino, 1929, II, pp. 235-286; Giovanni Maria Bertini: «Torquato Tasso e il Rinascimento spagnolo», en Torquato Tasso. Milano, Ed. Marzorati, 1957, pp. 607-671; Alessandro Tortoreto: «Il Tasso in Ispagna e Portogallo». Studi tassiani, I, (1951), pp. 69-77; A. Tortoreto: «Il Tasso europeo ed extra-europeo: periplo bibliografico». Italianistica, I, (1972), n. 1.

13 Juan Sedeño: Ierusalem libertada, poema heroyco de Torquato Tasso. Madrid, Pedro Madrigal, 1587. [Gallardo, IV, 3899].

14 Bartolomé Cayrasco de Figueroa: Goffredo Famoso. Poema heroyco de Torcato Tasso, cavallero Ferrarés. Do se trata la Conquysta de Hyerusalén: traducido de lengua Toscana en castellana. BNM, Ms. 4272. Ha sido editado por A. Cioranescu: Torquato Tasso. Jerusalén libertada, traducción de Bartolomé Cairasco de Figueroa. Tenerife, Aula de Cultura, 1967.

15 Antonio Sarmiento de Mendoça: La Gierusalemme liberata de Torquato Tasso. Madrid, Diego Díaz de la Carrera, 1649. [Gallardo, IV, 3889].

16 Vid. Francisco de Sosa: Versiones castellanas de la «Jerusalén libertada» de Torquato Tasso. Estudio bibliográfico. México, 1885. José Amador de los Ríos: «Estudios críticos sobre la Jerusalén libertada de Tasso». Revista española de ambos mundos, IV, (Madrid, julio de 1885), pp. 26-44; 418-439. F. Pierce: La poesía épica..., pp. 368-369. J. Arce: Tasso y la poesía..., pp. 36-39.

17 F. Pierce: La poesía épica..., p. 305. 
cantos, que recoge las leyendas relacionadas con Santiago. «La aparición de la Virgen y el relato de las primeras evangelizaciones españolas son motivos más propios de una vida de santos que de un poema épico tassesco, pese a las evidentes

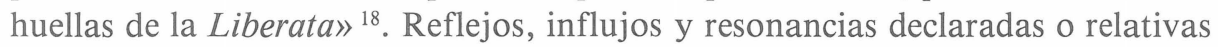
se localizan en poemas tales como la Conquista de la Bética (1603), en veinticuatro cantos, de Juan de la Cueva ${ }^{19}$, el Pelayo (1605), veinte cantos, de Alonso López Pinciano, la Primera parte de la Murgetana (1608) de Gaspar García Ortiz -el Oriolano-, la Jerusalén conquistada (1609) de Lope de Vega, en veinte cantos, la España defendida (1612), catorce cantos, de Cristobal Suárez de Figueroa, los Amantes de Teruel (1616), en veintiséis cantos y verso suelto, de Juan Yagüe de Salas, la Hespaña libertada (1618), veinte cantos, de Bernarda Ferreira de Lacerda, La Hispálica (1618?) de Luis de Belmonte Bermúdez, en doce cantos, el Poema heroico del assalto y conquista de Antequera (1627), veinte cantos, de Rodrigo de Carvajal y Robles ${ }^{20}$, El Fernando, o Sevilla restaurada (1632), veinte cantos, redondillas, de Juan Antonio de Vera y Figueroa, el Poema heroico de la invención de la cruz, por el emperador Constantino Magno (1648), veintidós cantos, de Francisco López de Zárate, la Nápoles recuperada por el rey don Alonso (1651), en doce cantos, de Francisco de Borja, o la Neapolisea (1651), ocho cantos, de Francisco de Trillo y Figueroa ${ }^{21}$.

Además de la profunda huella de los italianos no puede menospreciarse la impronta del Laberinto de Fortuna (1444) de Juan de Mena (1411-1456), conocedor profundo de la lengua latina y admirador de Virgilio, de Lucano y de Dante Alighieri. Del Laberinto extrajeron los poetas del siglo XVI no pocos materiales retóricos, pasajes modélicos y un buen número de cultismos léxicos ${ }^{22}$.

Por otra parte, una porción muy considerable de las obras aparecidas a lo largo del siglo XVII acusaron también el influjo de dos de los poemas más famosos, prestigiosos y significativos del siglo anterior: La Araucana (primera parte, 1569) de Alonso de Ercilla, y Os Lusíadas (1572) ${ }^{23}$ de Luis Vaz de Camões. El primero, configurado definitivamente en treinta y siete cantos [primera parte, Madrid, 1569; segunda parte, Zaragoza, 1578; tercera parte, Madrid, 1589], con una técnica descriptiva imitada de Virgilio y de Lucano, canta la guerra entre el heroico pueblo de Arauco y los conquistadores españoles, vista por el poeta bajo el prisma de la comprensión y de la simpatía de los que luchan por su libertad y por su independencia. Es verdad que algunos preceptistas subestimaron su valor

18 Ibídem, p. 308.

19 Sobre este asunto, vid. José Cebrián García: «Juan de la Cueva, poeta narrativo». El Barroco en Andalucía. Córdoba, Universidad-Diputación-Monte de Piedad, 1984-1987, 7 vols., IV, pp. 51-58.

20 Vid. la ed. de Francisco López Estrada: Poema del asalto y conquista de Antequera (Lima, 1627). Madrid, Real Academia Española, 1963.

21 Sobre el influjo tassiano en la épica española del Siglo de Oro, vid. F. Pierce: La poesía épica..., pp. 305-318, y J. Arce: Tasso y la poesía..., pp. 43-57.

22 Vid. María Rosa Lida de Malkiel: Juan de Mena, poeta del prerrenacimiento español. México, Fondo de Cultura Económica, 1950, esp. pp. 491 ss.

23 De las dos eds. de 1572 hay una magnífica repr. facsimilar: Os Lvsíadas. Lvís de Camões. Reprodução paralela das duas edições de 1572. Lisboa, Imprensa Nacional-Casa da Moeda, 1982. 
literario por haberse apartado de la verdad histórica y por reducir a un segundo plano a los héroes españoles, mas no decreció por ello la predilección de sus comtemporáneos y la estima de sus continuadores, entre los que destaca Pedro de Oña con el Arauco domado (1596) ${ }^{24}$. Por lo que respecta a la obra de Camões, no cabe la menor duda de que su impronta fue mucho mayor en la literatura portuguesa, pero poco después de 1572 comenzaron a publicarse las versiones castellanas, también en octavas, de Benito Caldera (1580) ${ }^{25}$, Luis Gómez de Tapia $(1580)^{26}$ y Henrique Garcés (1591) ${ }^{27}$, abundancia que evidencia la difusión y prestigio del gran poema ultramarino, acusada por el bilingüismo portugués, en la España de las postrimerías del siglo XVI ${ }^{28}$. No puede dejar de recordarse que bien entrado el siglo siguiente se publicó en Madrid Os Lusíadas (1639), en portugués, con unos extensos y documentados comentos castellanos de Manuel de Faria e Sousa ${ }^{29}$ que no fueron del agrado del Santo Oficio ${ }^{30}$.

Las teorías neoaristotélicas fueron defendidas con ahínco en los Discorsi del poema eroico (1594) por Torquato Tasso, elaborados a partir de los Discorsi dell'arte poetica, compuestos hacia 1565 y publicados en 1587 . Como se sabe, los principios de imitación, verosimilitud y unidad — cimentados en la Poética de Aristóteles - son los que marcan las principales pautas doctrinales. Tasso prescribía que el argumento debía sacarse de la historia, defendía la presencia de lo «maravilloso», siempre que no atentara a las creencias religiosas del lector, y señalaba como fin del poema heroico la existencia de la «verosimilitud», no necesariamente de la «verdad», y, además, aceptaba la relativa unidad de acción y la presencia de episodios secundarios y digresiones siempre y cuando no desembo-

24 Guía bibliográfica importante es la de August J. Aquila: Alonso de Ercilla Zúñiga: A Basic Bibliography. London, Grant \& Cutler [Research Bibliographies and Checklists, 11], 1975.

25 Las Lusiadas de Luys de Camões, Traduzidos en octava rima Castellana por Benito Caldera. Alcalá de Henares, Juan Gracián, 1580. [Gallardo, II, 1525].

26 La Lusiada, de el famoso Poeta Luys de Camões, traduzida en verso castellano de Portugués, por el Maestro Luys Gómez de Tapia. Salamanca, Joan Perier, 1580. [Gallardo, III, 2371].

27 Las Lusiadas de Luys de Camões, Traduzidos de Portugués en Castellano por Henrique Garcés. Madrid, Guillermo Druoy, 1591. [BLH, VII, 3705].

28 Sobre las relaciones de Camões con España, vid. entre otros, Dámaso Alonso: «La recepción de Os Lusíadas en España». Boletín de la Real Academia Española, LIII, (Madrid, 1973), pp. 33-61; Eugenio Asensio: La fortuna de «Os Lusíadas» en España. (1572-1672). Madrid, Fundación Universitaria Española, 1973; del mismo: «España en la épica portuguesa del tiempo de los Felipes (1580-1640)», en Estudios portugueses. París, Fundação Calouste Gulbenkian, 1974, pp. 455-496; del mismo: «Camões en la poesía española de los siglos XVI y XVII». Arquivos do Centro Cultural Português, XV, (París, Gulbenkian, 1980), pp. 111-132. Eugenio Asensio / José V. de Pina Martins: Luís de Camões. El humanismo en su obra poética. Los Lusíadas y las Rimas en la poesía española. París, Fundação Calouste Gulbenkian-Centro Cultural Português, 1982. Vid. también Alonso Zamora Vicente, Jacinto do Prado Coelho, José Filgueira Valverde, Vítor Manuel de Aguiar e Silva: Cuatro lecciones sobre Camoens. Madrid, Fundación Juan March-Eds. Cátedra, 1981.

29 Lusíadas de Luis de Comoens, Príncipe de los Poetas de España. Madrid, Juan Sánchez, 1639, 4 vols. en dos tomos. Hay magnífica ed. facsimilar, con introducción de Jorge de Sena, Lisboa, Imprensa Nacional-Casa da Moeda, 1972.

30 Lusíadas de Luis de Camoens..., I, «Introdução», p. 35n. 
caran en la acción principal ${ }^{31}$. En España, Alonso López Pinciano tuvo muy en cuenta esta teorías en su Philosophía antigua poética (1596) ${ }^{32}$ : «supuesta, pues, la definición, epiloguemos assí las qualidades de la épica: primeramente, que sea la fábula fundamentada en historia; y que la historia sea de algún príncipe digno y secular; y no sea larga por vía alguna; que ni sea moderna ni antigua; y que sea admirable; ansí que, siendo la tela de la historia admirable, y, en la fábula verisímil, se haga todo, que de todos sea codiciada y a todos deleytosa y agradable» ${ }^{33}$.

Lo mismo puede decirse de las Tablas poéticas (1617) del licenciado Francisco Cascales, uno de los preceptistas hispanos más preocupados por las discusiones teóricas y por los problemas formales. Tras declarar su admiración y simpatía por los «Cantos o Capítulos de Dante Alighiero», por los «Triumphos famosos del Petrarca», por «las Trecientas de Juan de Mena» y por una larga serie de poemas épicos italianos y españoles -él mismo fue autor de uno de esta índole-, definió el género como «imitación de hechos graves y excelentes, de los quales se hace un contexto perfecto y de justa grandeza, con un decir suave, sin música y sin bayle, ora narrando simplemente, ora introduciendo a otros a hablar» ${ }^{34}$.

Pero las normas aconsejadas por los preceptistas no fueron seguidas siempre por los poetas. Lo que caracteriza a buen número de estos poemas es, en palabras de A. Prieto, «su permeabilidad o contaminación, y su movimiento descanonizador». «Con La hermosura de Angélica tenemos ya un claro ejemplo del quebrantamiento de los preceptos aludidos, tenemos un efectivo desorden [...] y una evidente proyección biográfica [...] Este valor biográfico [...] implica, más allá de la variedad ariostesca, una perturbación del más abierto canon preceptista. La figura lopesca de Angeloro, nacido de Angélica y Medoro, es una evidente señal de la conciencia de Lope de haber perdido la materia épica en su Angélica y como el anuncio de una segunda parte reparadora donde, entre armas, se cumpliría la apoteosis genealógica y política del futuro Felipe III como «defensor fidei».

Con su desarmonía y su proyección fuertemente amorosa, La hermosura de Angélica nos está exteriorizando la varia complejidad de elementos que constituyen la épica renacentista y que responden, en natural transformación, a su origen italiano, a la complejidad de elementos que vienen a formar, con el Innamorato, lo que denomino el canon de Ferrara. A este canon, en el que ya vive la proyec-

31 Vid. Giovanni Caravaggi: «Evoluzione di un presupposto aristotelico nell'epica ispanica del tardo Rinascimento (con uno studio su alcuni prologhi e proemi)». Cultura neolatina, XXIII, (1963), pp. 18-71.

32 Sobre los débitos del Pinciano a los Discorsi, vid. G. M. Bertini: «Torquato Tasso e il Rinascimento»..., pp. 633 ss.; Sanford Shepard: El Pinciano y las teorías literarias del Siglo de Oro. Madrid, Ed. Gredos, $1970^{2}$, pp. 115-126.

33 [Alonso] López Pinciano: Philosophía antigua poética. Madrid, CSIC, 1973, 3 vols., III, p. 178. [Ed. de Alfredo Carballo Picazo].

34 Cito a través de la ed. Tablas poéticas del Lic. Francisco Cascales. Madrid, Antonio de Sancha, 1779, p. 111. Hay reedición, con excelentes comentarios, de Antonio García Berrio: Introducción a la Poética clasicista: Cascales. Barcelona, Ed. Planeta, 1975, 2a ed., Madrid, Taurus Eds., 1988. El comentario a la definición de «epopeya» en pp. 257-259. 
ción biográfica en amor, se suma un contexto español de tradición más o menos épica y más o menos culta que anima y distingue la natural transformación o evolución de la épica» ${ }^{35}$.

Ese conjunto de elementos y peculiaridades varias que configuran la épica renacentista demuestra, en cierto modo, la existencia de una oposición relativa —nunca una incomunicación - entre los preceptistas y los poetas. «En líneas generales, esta oposición se establece porque los preceptistas y gramáticos explican lo que utópicamente (fuera de su tiempo) debiera ser el poema épico, mientras que los poetas realizan, con su actualidad, su poema. Y mientras los preceptistas quedan anclados en unas normas del pasado que ayuntan a Homero y a Aristóteles, los poetas van caminando en la evolución de su tiempo, siguiendo el propio carácter de continuidad que ofrecía el poema de Boiardo y recoge ya Ariosto» ${ }^{36}$.

Por tal motivo, cuando José Pellicer y Tovar publica su Epilogo de los preceptos del poema heroico (1625) y prescribe que el protagonista de esta clase de obras debe ser «señor soberano en quien concurran todas las perfecciones morales [...] hermoso, valiente, intrépido, sabio, prudente, cuerdo, político, maduro, experimentado, religioso, justo, clemente, liberal, magnánimo, vigilante, severo, astrólogo, astrónomo, geógrafo, piloto, táctico, matemático i versado en las lenguas i ciencias, de noticias, agilidad i destreça sobre todas las personas que introduce, para que tenga fin bienaventurado i glorioso» ${ }^{37}$, no está haciendo más que repetir toda una tópica recurrente, heredada de sus predecesores, sin considerar la realidad tangible de los poemas narrativos de su tiempo.

A. Prieto, que ha puesto de relieve en la configuración de la épica española renacentista la existencia de dos vías interrelacionadas - la de los poetas y la de los preceptistas-, ha señalado la importancia relevante del «canon de Ferrara», conjunto de teorías emanadas en la segunda mitad del Cuatrocientos en los ambientes literarios de la signoria estense, formalizadas por Boiardo y elevadas a niveles de mayor prestigio por Ariosto en el desarrollo del género en España ${ }^{38}$. De este modelo codificado, «estimulante, aprehensible y modificable» se destacan cinco aspectos fundamentales, recogidos por nuestra poesía narrativa: 1. Utilización de la octava real como forma métrica por excelencia, capaz de adaptarse tanto a lo lírico como a lo narrativo. 2. Entendimiento de la épica culta como individualización literaria de una materia pre-existente, relativamente lejana o cercana al momento de la poetización, que adquiere rango de leyenda mítica dotada de argumento y/o de personajes. La función del poeta no es otra que nobilitare - ennoblecer - la materia legendaria pre-existente, añadiendo, cuando ello sea oportuno, elementos de su propia invención y proporcionando un nuevo enfoque o un nuevo tratamiento de esa materia. 3. Confirmación del valor inmortal del

35 A. Prieto: «origen y transformación»..., p. 121.

36 Ibídem, pp. 124-125.

37 Juan Sánchez: Academias literarias del Siglo de Oro español. Madrid, Ed. Gredos, 1961, pp. 90-91. Vid. también A. Prieto: «Origen y transformación»..., p. 125.

38 Sobre el influjo del Innamorato en la épica hispánica, vid. Giovanni Caravaggi: Studi sull'epica ispanica del Rinascimento. Pisa. Università di Pisa, 1974, esp. pp. 29 ss. 
poeta, capaz de mitificar y glorificar en su obra. 4. Capacidad de proyección autobiográfica en los personajes o en determinadas secuencias del poema. 5. Variedad de acciones y de personajes en la configuración del poema épico ${ }^{39}$.

Pero además, junto a la aceptación global y a la relativa dependencia del canon, la épica culta española muestra también una cierta oposición de carácter nacionalista. Es muestra de ello Las lágrimas de Angélica (primera parte, 1586) de Luis Barahona de Soto, «poema heroico de exaltación nacional que, bajo la cobertura caballeresca y el pretexto genealogista, y según unas normas épicas prefijadas y aceptadas como heroicas por los eruditos del siglo XVI, se proponía cantar a Bernardo del Carpio como paladín de la Cristiandad y como símbolo de la independencia española: propósito que inserta al poema de Barahona en lo que se ha llamado, muy acertadamente «momento bernárdico» de la literatura española del Siglo de Oro, y en el que nuestros escritores trataron de salvar del olvido a los héroes hispanos y sus hazañas gloriosas» ${ }^{40}$.

Si se da un ligero repaso a la producción épica de los Siglos de Oro ${ }^{41}$, tan vasta como compleja y variada, se comprobará que un considerable número de piezas carecen de intencionalidad nacionalista y atentan contra los presupuestos del «canon de Ferrara». Se ha repetido insistentemente que el espíritu emanado de Trento, el interés suscitado por la temática histórica y religiosa en los comienzos del siglo XVII y la restauración de la preceptiva neoaristotélica contribuyeron a frenar el influjo del Orlando furioso — que ayuntaba los elementos de la ficción novelesca y el didactismo moralizante- en nuestras letras. Sin embargo, conviene que nos adentremos en la problemática del subgénero de asunto mitológico. Resulta evidente que junto a los poemas de corte heroico o religioso, de asunto ultramarino, novelesco, histórico o burlesco, se publicó también un buen número de piezas de tema mitológico cuyas características estructurales son las mismas que configuran al resto de los subgéneros épicos. La existencia de esta «série mythologique» ${ }^{42}$ obedece también al principio de la imitatio aristotélica. Si las composiciones de asunto heroico o histórico partían de una materia argumental preexistente (crónicas, leyendas, etc.), las de corte mitológico arrancan también de una base previa, contenida la mayor parte de las veces en el acopio fabuloso de las Metamorfosis de Ovidio. Por ello, el poeta, siguiendo el nobilitare del canon ferrarés, no hace otra cosa que reelaborar -individualizar- esa materia.

Pero no siempre se extrajo la materia de la «biblia de los gentiles». En el caso de Los amores de Marte y Venus de Juan de la Cueva — valga como simple

39 Vid. A. Prieto: «Origen y transformación»..., pp. 128-143. En atención a la Angélica de Barahona, vid. J. Lara Garrido: «Las lágrimas de Angélica, en el canon de Ferrara (celebración genealógica y nacionalismo)», en Luis Barahona de Soto..., pp. 23-34.

40 E. Lacadena: Nacionalismo y alegoría..., p. 16.

41 Vid., p. e. Cristóbal Cuevas García: «La poesía épica del Siglo de Oro», en Historia de la literatura española. II. Renacimiento y Barroco. Madrid, Taurus Eds., 1980, pp. 299-315, o Frank Pierce: «La épica literaria española. Examen crítico», en Homenaje al Instituto de Filología y Literaturas Hispánicas «Dr. Amado Alonso». Buenos Aires, 1975, pp. 310-331.

42 Georges Cirot: «Coup d'oeil sur la poésie épique du Siècle d'Or». Bulletin hispanique, XLVIII, (Bordeaux, 1946), p. 317. 
ejemplo- la materia pre-existente procedió de cierta digresión de la Odisea ${ }^{43}$, básicamente. En otros casos, la pieza es producto de un proceso depurado de recreación mimética, consecuencia de la conjunción de varias versiones diferentes de un mismo mito. En todo caso, se trata de un subgénero muy en boga a lo largo de los siglos XVI y XVII que alcanzó también relativa difusión y grande aceptación. Basta sólo con repasar el Catálogo de poemas épicos de Cayetano Rosell ${ }^{44}$ —que es aún de utilidad- o la bibliografía de ediciones de Antonio Papell ${ }^{45}$ para comprobarlo.

Una de las características más acusadas de la épica culta es, sin duda, su diversidad extensiva. Un buen número de obras copiaron la disposición narrativa de los grandes modelos grecolatinos e italianos, dignos de imitación. La distribución en veinticuatro cantos - la cifra homérica - fue seguida, entre otros, en la Conquista de la Bética (1603) de Juan de la Cueva; los doce cantos de la Eneida en La Hispálica (1618?) de Luis de Belmonte Bermúdez; los veinte de la Gerusalemme liberata en determinadas composiciones de influjo tassiano que ya hemos tenido ocasión de citar. Otras piezas narrativas, muy al contrario de éstas, ofrecen una disposición muy diferente. Mucho más extensas son, por ejemplo, la Universal redempción (1584) de Francisco Hernández Blasco, en cincuenta y cinco cantos, aumentados a ochenta y seis en las ediciones del siglo XVII, el Carlo famoso (1566) de Luis Zapata, cincuenta cantos, El león de España (1586) de Pedro de la Vezilla Castellanos, veintinueve cantos, o la Historia de la Virgen Madre de Dios, María (1618) de Antonio de Escobar y Mendoza, en treinta y seis cantos. Pero además se cultivó también una variedad mucho más breve, cuya extensión gira en torno a los cinco cantos. Cabe citar, como simples botones de muestra, La creación del Mundo (1615) de Alonso de Acevedo, en siete cantos, o la Limpia concepción de la Virgen (1617) de Baltasar Elisio de Medinilla y la Corona trágica (1627) de Lope de Vega, ambas en cinco cantos. Dentro de la serie mitológica destacan las Transformaciones y robos de Júpiter (1619) de D. Juan de Espínola y Torres, en seis, el Orfeo (1624) — cinco cantos_ de Juan de Jáuregui, o La Filomena (primera parte, 1621) de Lope de Vega y el Endimión (1627) de Marcelo Díaz Callecerrada, ambos en tres cantos.

El asunto mitológico abunda también en los poemas más breves del género: los que se reducen a la materia imprecisa de un solo canto y no suelen sobrepasar en demasía la centena de octavas. «The canto épico, however, as it name declares, is a single canto complete in itself, which develops, in anything from fifty to one

43 Vid. José Cebrián García: La fábula de Marte y Venus de Juan de la Cueva. Significación y sentido. Sevilla, Universidad de Sevilla, 1986, pp. 108-120.

44 Cayetano Rosell: «Catálogo de poemas castellanos heroicos, religiosos, históricos, fabulosos y satíricos», en Poemas épicos. II. Madrid, Eds. Atlas, 1948 [BAE, XXIX], pp. XIX-XXVII.

45 A. Papell considera los poemas narrativos de tema mitológico como un subgénero de la épica novelesca. Vid. «La poesía épica culta»..., en Historia general..., II, p. 782. Como repertorios, vid. -entre otros- los de E. de Ochoa: Tesoro de los poemas españoles épicos, sagrados y burlescos. París. Baudry, 1840, pp. XVI-XXXII; L. A. de Cueto: «Catálogo de poemas castellanos heroicos, místicos, históricos, burlescos, etc., del siglo XVIII», en Poetas líricos del siglo XVIII. III. Madrid, Eds. Atlas, 1953 [BAE, LXVII], pp. VII-XIV; F. Pierce: «Catálogo cronológico de poemas publicados entre 1550 y 1700», en La poesía épica..., pp. 327-362. 
hundred octavas, an episode or short tale of heroic substance, the formalistic merit of which is its condensation and compactness» ${ }^{46}$. Como en el caso de los poemas mayores, en esta épica culta en miniatura es también corriente el hecho lógico de la diversidad temática, cuestión que llega a dificultar las premisas de una definición más ajustada y concisa.

El origen de esta clase de composiciones épicas está, una vez más, en Italia. «The varied literature in Latin of the late quattrocentro and early cinquecento, which gave some excellent specimens of elegant and inspired verse, also included, side by side with longer Virgilian poems, several one-canto poemetti of epic form, descriptive, martial and eulogistic, and counted among the cultivators of these short poems such illustrious names as Bembo and Sannazaro, whose Latin verse is held to be a model of humanistic literary achievements. In the same way and largely by derivation, the ottava rima was used in poemetti which ranged in subject from pure lyrical outbursts to accounts of war-like deeds, and which frequently blended epic material with mythological and pastoral themes or the praise of patrons and their families. On these vernacular poems the Clorida of Luigi Tansi1lo, which has for one of its protagonists the patron of Garcilaso, D. Pedro de Toledo, Viceroy of Naples, and the Ninfa tiberina, of Francesco Maria Molza, which praises the painter Sebastiano del Piombo, are regarded as the best. They appeared respectively in Giolito's Scelta di stanze $(1553,1563)$, and the Scelta (1571), both published at Venice and both given over entirely to these short narrative poems of hybrid character which soon gained wide diffusion. The first Scelta also contained several examples of favole in the same metre and of similar length. These were generally of Ovidian origin as to theme and clearly form forerunners, as were the more purely heroic stanze in the case of the canto épico proper, of the mass of fables in verse that were to flood the anthologies and the poetic contests of the seventeenth century. It might well be held that this was the age of European mythological literature par excellence: Lope and Góngora, Marini and Chiabrera, Spenser and Shakespeare, Drayton and Dryden, were among the countless poets and poetasters who lovingly drew upon the treasures of the Metamorphoses and the Heroides» ${ }^{47}$.

Pero aunque F. Pierce se refiere a la fábula y al canto épico como formas de expresión diferenciadas, aunque muy parecidas, acaso lo que las separa - los elementos que de algún modo pueden resultar distintivos-, no queda delimitado con mediana claridad. "Of the many lyrical shapes taken by Ovidian Tales, the Canto épico proved to be one of the most enduring, and it will be seen that several of the examples of the genre hardly deserve the strict title of epic. Indeed, not only the fábulas, but the cantos épicos of obvious heroic character have traditionally been inserted in lyrical collections. For this the shortness of the form and its recurring lyrical passages may offer some justification, but the fact remains that the true canto épico is far more narrative than lyrical, although again it can-

46 Frank Pierce: «The canto épico of the Seventeenth and Eighteenth Centuries». The Hispanic Review, XV, 1, (Philadelphia, 1947), p. 1.

47 Ibídem, pp. 2-3. 
not always be decided to what muse belong certain short narrative poems» ${ }^{48}$. Por lo que respecta al siglo XVII, F. Pierce estudia cinco piezas breves de temática harto diferente «representative of this interesting little genre which more than held its own with older and more established forms». Se trata de la Fábula de Genil (1605) de Pedro Espinosa, en treinta octavas, «an example of the pure fable in ottava rima, but it will be seen that some others can be more readily classed as heroic for their greater use of epic devices»" ${ }^{49}$, el Canto de Jacob y Raquel (1648), de asunto bíblico (ciento once octavas), y el Canto de Marco Antonio y Cleopatra (1663), de tema histórico antiguo (ciento siete octavas), ambos de Francisco de Borja, príncipe de Esquilache, el Poema heroico a Cristo resucitado (publicado en 1670), cien octavas, de Francisco de Quevedo, y La Raquel (1650), en setenta y siete octavas, de Luis Ulloa Pereira, inspirada en la célebre leyenda de Alfonso VIII y la judía de Toledo ${ }^{50}$.

La épica culta hispánica no es cosa, sólo, de largas y farragosas epopeyas. La forman también estos poemitas en miniatura, no estudiados todavía como se merecen. Porque para hacerse una idea cabal de la literatura española de la Edad de Oro no basta con conocer el teatro, la novela picaresca, el romancero artístico o las grandes obras maestras del Barroco: «il faut s'être promené sous les frondaisons de la poésie heroïque, dans ce «paseo» où l'on retrouve l'athmosphère de l'époque, les manières quelques peu apprêtées qu'imposait la mode italienne, l'allure décidée des conquérants du Nouveau Monde, le culte du passé national et de l'histoire religieuse; et aussi le goût du plaisant, de l'humour» ${ }^{51}$.

48 F. Pierce: «The canto épico»..., p. 3.

49 Sobre el concepto de fábula vid. J. Cebrián García (ed.): Juan de la Cueva. Fábulas mitológicas y épica burlesca. Madrid, Editora Nacional, 1984, pp. 50-51, nota 146.

50 F. Pierce: «The canto épico»..., pp. 8-11. Este mismo investigador afirma (p. 6, n.) que el romance «would seem to have been a more common medium for the fable», pero también los poemas de asunto mitológico en octavas fueron muy abundantes.

51 G. Cirot: «Coup d'oeil»..., pp. 327-328. 
